\title{
Plasma Exchange for Renal Disease: Evidence and Use 2011
}

\author{
W.F. Clark* \\ London Health Science Centre, Western University Canada, Lawson Health Research Institute and \\ Program of Experimental Medicine at Western University Canada
}

\begin{abstract}
Over the past 37 year the role of plasma exchange in the treatment of patients with renal disease has undergone several changes. The majority of the changes for the use of plasma exchange relied on randomized control trials and delineations of mechanisms that potentially would benefit from the use of plasma exchange. Over the past 11 years plasma exchange indications for renal disease, the absolute numbers have been relatively unchanged but the indications are quite different. The Canadian Apheresis Group indicated in 2010 that TTP/HUS is still the number 1 indication at $63 \%$ of the total plasma exchange activity for renal disease but $\mathrm{P}$ and $\mathrm{C}$ ANCA Vasculitis had risen to $14 \%$ followed by renal transplant at $10 \%$, Goodpasture's Syndrome at $6 \%$ and transplant FSGS at 5\% with Cryoglobulinemia $2 \%$ and Myeloma Nephropathy had dropped dramatically to less than $1 \%$ with no cases of SLE reported. This report describes the most common indications for plasma exchange in patient's with renal disease and the evidence that supports it's use in 2011. J. Clin. Apheresis 27:112-116, 2012. @2012 Wiley Periodicals, Inc.
\end{abstract}

Key words: therapeutic plasma exchange; renal; therapeutic apheresis; ANCA; myeloma

\section{INTRODUCTION}

The introduction of plasmapheresis, as a form of treatment for renal disease, was initially reported by Martin Lockwood et al. in 1975 in the British Medical Journal in a patient who suffered from Goodpasture's Syndrome and received both immunosuppressive treatment and plasmapheresis and recovered from both his pulmonary hemorrhage and his renal failure [1]. Plasmapheresis, since that period of time, has been employed in a variety of kidney disorders and has been directed primarily at two mechanisms, (1) removal of unwanted substances, for example Goodpasture's Syndrome where you remove the anti-Glomerular Basement Membrane antibody that cross reacts with the basement membrane of the kidney and lungs and (2) removal of an unwanted substance and addition of a deficient substance for example in TTP where you remove the antibody to ADAMTS13 and replace it with ADAMTS13 in the plasma product. The Canadian Apheresis Group (CAG) formed a registry in 1980 and has collected data on all apheresis procedures throughout Canada from that time point until the present. The CAG has traced the patterns and changes in the application of this therapy in light of growing evidence. In 1981, the five most common indications for plasma exchange were: (1) Myasthenia Gravis, (2) SLE, (3) TTP, (4) Guillain Barre Syndrome, and (5) Waldenström's Macroglobulinemia. These procedures took about $55 \%$ of the entire total procedures $(3,189)$ done in Canada that year. By 1997, 8,208 procedures were performed and $81 \%$ were done for only five conditions. The number one condition was TTP, which took up $39 \%$ of the activity; Myasthenia Gravis 14\% of the activity; Chronic Inflammatory Demyelinating Polyneuropathy 14\%; Waldenström's 8\%; and Guillain Barre $6 \%$. In a report in the Annals of Internal Medicine in 1999 , we noted that although four of the five top indications were the same in 1981 and 1997, three indications had dropped from five most frequent to the least frequent over that time period. These changes were thought due to the availability and quality of evidence [2].

By 2010 the CAG reported 9246 plasma exchanges in Canada and $25 \%$ of them were for TTP/HUS, $21 \%$ for myasthenia gravis, $6 \%$ for chronic inflammatory demyelinating polyneuropathy, and $5 \%$ for $\mathrm{P}$ and $\mathrm{C}$ ANCA Vasculitis and another 5\% for Waldenström's. Thus, there had been a significant change again in the five most common indications, with approximately two-thirds of all the plasma exchange activity with the

*Correspondence to: W. F. Clark, MD, FRCPC, FACP, FASN, London Health Sciences Centre, Walkerton Health Study, University of Western Ontario, Lawson Health Research Institute and Program of Experimental Medicine. E-mail: William.Clark@LHSC.ON.CA

Received 4 February 2012; Accepted 21 February 2012

Published online 25 April 2012 in Wiley Online Library (wileyonlinelibrary.com).

DOI: $10.1002 /$ jca.21221 
TABLE I. What About PE for Renal?

\begin{tabular}{ll}
\hline Top Six 2001 $N=3,703$ & Top Six 2010 $N=3,704$ \\
\hline TTP/HUS (72\%) & TTP/HUS (63\%) \\
Myeloma cast N (8\%) & P \& C ANCA vasc (14\%) \\
Goodpasture's (5\%) & Renal transplant (10\%) \\
Cryoglobulinemia (5\%) & Goodpasture's (6\%) \\
Transplant (4\%) & Transplant FSGS (5\%) \\
P \& C ANCA vasc (3\%) & Cryoglobulinemia (2\%) \\
\hline
\end{tabular}

exception of Waldenström having randomized control trials to support their usage.

What about the role of plasma exchange for renal disease? There have been significant changes from 1981 to the present time and more so from 2001 to 2010. Interestingly, over this time period the number of exchanges carried out for renal indications is approximately the same, being 3,703 in 2001 and 3,704 in 2010 , but there has been a significant change in the proportion and order of entities. In 2001, TTP/HUS represented $72 \%$ of the plasma exchange procedures being done in terms of renal followed by myeloma cast nephropathy at $8 \%$, Goodpasture's at 5\%, Cryoglobulinemia at $5 \%$ with transplants around $4 \%, \mathrm{P}$ and $\mathrm{C}$ ANCA Vasculitis at 3\%, Lupus at $\sim 1 \%$ and glomerulonephritis (GN) not rapidly progressive glomerulonephritis (RPGN) at less than 1\%. By 2010 TTP/HUS was still the number one indication but this was only $63 \%$ of the total and P and C ANCA Vasculitis had risen to $14 \%$ followed by renal transplant $10 \%$, Good Pasture's Syndrome 6\%, Transplant FSGS 5\%, Cryoglobulinemia $2 \%$, myeloma cast nephropathy less than $1 \%$ and SLE no cases (Table I).

\section{DISCUSSION}

The diagnosis of TTP/HUS represents an amalgamation of two entities: TTP and HUS. Each defined as primary or secondary to a disease or clinical context. Pathologically these patients all have thrombotic microangiopathy with thrombi in the microvasculature and thrombocytopenia and microangiopathic hemolysis in the peripheral blood and dysfunction of an end organ. However, the diagnosis of TTP/HUS is one of therapeutic convenience, but these two clinical expressions of thrombotic microangiopathy, TTP and HUS, have different origins. The original case of TTP was described by Eli Moskowitz in 1925 and this was a 16-year-old girl who presented with pallor, petechiae, fever, hemolytic anaemia, a partial paresis, went into a coma and died. An autopsy revealed widespread hyaline thrombosis [3]. The next thrombotic microangiopathy to be described was HUS by Gasser in 1955, in five children who had developed a thrombotic microangiopathy after diarrheal illness and they had a triad of thrombocytopenia, hemolytic anaemia and kidney failure and the new diagnosis of hemolytic uremia syn- drome, which over time evolved to the diagnosis of diarrheal HUS secondary in most cases to E.coli 0157:H7 [4].

In 1959, Rubenstein described an 11-year-old female who presented with the diagnosis of an obvious case of TTP and responded to an exchange transfusion. They indicated that they really did not have the answers as to why the exchange transfusion worked; however, they had noted in a previous case that when the patient required massive blood transfusion to treat GI bleeding they actually demonstrated an improvement in their clinical picture and their thrombocytopenia. However, they stopped the massive transfusion and the patient subsequently died, whereas this 11-year-old girl had a sustained remission following two complete exchanges [5]. This led to the report by Bukowski in 1977 of two cases of TTP who he had first treated with plasma exchange and both had entered complete remission. He had been guided by his past 16 years in which nine of 15 patients that received exchange transfusions recovered and therefore he thought it was logical to proceed with plasma exchange [6]. Again, the concept of exchange and the removal of a toxin was thought to be central to the success of these two cases. In the same year, Byrne reported a young woman who was pregnant whom he used a variety of different blood product replacements to demonstrate that the remittive agent was in the plasma [7]. He presumed that the treatment was successful due to a deficiency which he was replacing with the plasma. The question arose following both Bukowski and Byrne findings as to what was being replaced or removed? In 1991 Rock attempted to answer that question with the Canadian Apheresis Group and reported on 102 patients with TTP/HUS who had been randomized to either receive plasma infusion or plasma exchange and there was a significant difference in survival; $63 \%$ in the plasma infusion group and $78 \%$ in the plasma exchange group at 6 months with the plasma exchange being superior to the plasma infusion [8]. The plasma exchange adds and removes whereas plasma infusion only adds. However, in the plasma exchange arm the patients did receive significantly more plasma than in the plasma infusion arm. The issue of what were we adding and what were we removing was addressed by Tsai and Leung and Furlan et al. in the New England Journal of Medicine in $1998[9,10]$. In the same issue Tsai reported that there are inhibitory antibodies against von Willebrand factor cleaving protease in acute TTP causing a functional deficiency which has a critical role in the pathogenesis of the platelet thrombosis. Furlan also demonstrated that the nonfamilial form of TTP is due to an inhibitor to von Willebrand factor cleaving protease just as Tsai had described but in the familial form he reported a constitutional deficiency of the protease and in HUS there was not a deficiency or inhibition of 
the von Willebrand factor cleaving protease [10]. Thus plasma exchange was removing the inhibitor and providing the protease.

Since that time a variety of authors and in particular Vesely and George et al., have reported their experience in measuring ADAMTS13 and its inhibitor and noted the mechanism is important in terms of understanding the disease process but it is only severely deficient due to inhibitor in about one-third of cases of TTP that respond to plasma exchange therapy [11]. The success of plasma therapy coupled with the almost certain mortality in the absence of treatment has led to the term TTP/HUS in adults. Therefore clinically we have gone from the diagnostic pentad (that Amorosi and Altman described in 1966) often made at the time of death to the more up-to-date clinical diagnosis of adult TTP/HUS [12].

Clinically we have a spectrum of HUS to TTP that can be either primary or secondary to the disease or clinical context. The success of plasma therapy has resulted in the coinage of the term adult HUS/TTP or TTP/HUS and the diagnosis is made if an adult patient has unexplained thrombocytopenia and hemolytic anemia with normal INR and an elevated lactate dehydrogenase secondary to tissue ischemia [13]. The secondary forms of TTP/HUS are as common as the primary form, as indicated by the report of Fujimura in over 738 patients with thrombotic microangiopathy [14]. A variety of studies have shown that although plasmapheresis is successful in both primary and secondary forms, it does not have a demonstrated therapeutic effect in patients who have TTP/HUS secondary to E. coli O157: H7, (DHUS), malignancy, mitomycin $\mathrm{C}$, allogeneic bone marrow transplantation or malignant hypertension. There are two predominant mechanisms in secondary thrombotic microangiopathy, the minority of cases being similar to the primary forms of TTP in which you have inhibition of ADAMTS13 protease with increasing von Willebrand factor multimers, but the majority demonstrate moderately reduced or normal ADAMTS13 with endothelial injury as the priming event. Table II serves to outline thrombotic microangiopathies by the level of their response to plasma exchange.

$\mathrm{P}$ and $\mathrm{C}$ ANCA Vasculitis has recently been shown in a randomized control trial of 137 patients to benefit from the use of plasma exchange. In the study by Jayne, 137 patients were randomized and had evidence of $\mathrm{P}$ or $\mathrm{C}$ ANCA Vasculitis with a creatinine of greater than $500 \mathrm{mmol} / \mathrm{L}$ and were treated with bolus methylprednisolone and cyclophosphamide or plasma exchange and cyclophosphamide [15]. The group receiving the plasma exchange had a $24 \%$ reduction in the risk for progression to end-stage renal disease. These changes were significantly different; however patient survival and adverse event rates were similar.
TABLE II. Thrombotic Microangiopathy and Plasma Treatment

Thrombotic thrombocytopenic purpura/ hemolytic uremic syndrome (majority adults)

$\begin{array}{ll}\text { Primary } & \text { (1) Idiopathic or acquired* } \\ \text { Secondary } & \text { (1) Hereditary* } \\ & \text { (2) Drugs* except mitamycin C } \\ & \text { (3) Infection \# except confirmed E coli O157:H7 (NR) } \\ & \text { (4) Pregnancy\# } \\ \text { (5) Pancreatitis\# } & \text { (6) Stem cell transplant (NR) } \\ \text { (7) Occult or disseminated malignancy (NR) } \\ \text { (8) Malignant hypertension (NR) } \\ \text { Hemolytic uremic syndrome (majority children) }\end{array}$

\begin{tabular}{|c|c|}
\hline Primary & $\begin{array}{l}\text { Atypical hemolytic uremic syndrome } \\
\text { (abnormalities in complement regulation); } \\
\text { Complement factor H\#; Complement factor I\#; } \\
\text { Complement factor B\#; C3 convertase\#; } \\
\text { Thrombomodulin \# except membrane } \\
\text { co-factor protein (NR) }\end{array}$ \\
\hline Secondary & $\begin{array}{l}\text { Diarrheal hemolytic uremic syndrome (NR) } \\
\text { except neurologic }\end{array}$ \\
\hline
\end{tabular}

80-90\% Response, *; 50-70\% Response, \#; 0\% Response, NR.

A rapidly rising entity in terms of indications for plasma exchange is renal transplantation and this falls into four categories. The commonest indication in terms of the CAG data is for acute humeral rejection and there have been a variety of studies carried out using a wide range of immunosuppressive agents \pm splenectomy demonstrating benefit. As well similar success of 80 $100 \%$ has been noted in the treatment of ABO incompatible transplantation as well as transplantation in HLA highly sensitized recipients [16,17]. There is an interesting study done by Karthikeyan which used plasma exchange to treat patients who developed a TTP/HUS-like syndrome with calcineurin inhibitor therapy for their transplant. In the past, discontinuing the calcineurin inhibitor was associated with significant survival benefit. Certainly, 29 of the 29 patients did survive with the plasma exchange and interestingly enough, 23 of the 29 had sustained good graft function whereas in the past when the calcineurin inhibitor therapy was discontinued most grafts were lost [18].

The fourth commonest indication for plasma exchange use in Canada in renal disease is that of Goodpasture's Syndrome which harkens back to the original description of the treatment by Martin Lockwood et al. in the British Medical Journal in 1975 [1]. In 1978, Swainson et al. reported on three cases and by that time suggested that a control trial of this regimen is urgently required but it was not until 1985 that Johnson et al. carried out a randomized control trial on only 17 patients $[19,20]$. It was severely underpowered and the only difference was due to treatment allocation. Interestingly enough this is the only randomized control trail of the 2,146 publications listed in PubMed for plasma exchange in Goodpasture's Sydrome. 
The most convincing evidence for the use of plasma exchange comes from a retrospective review of 71 patients treated for confirmed anti-GBM antibody disease over 25 years, published by the Hammersmith Group [21]. They show that in patients who presented with a creatinine concentration of less than $500 \mathrm{mmol} /$ L $(n=19), 100 \%$ survived with the use of plasma exchange and immunosuppression and $95 \%$ had renal survival at 1 year and $84 \%$ patient and $74 \%$ renal survival at last follow-up. Patients who presented with creatinine concentration of $500 \mathrm{mmol} / \mathrm{L}$ or more $(n=13)$ and did not require immediate dialysis, the patient and renal survival were 83 and $82 \%$ at one year and 62 and 69\% at last follow-up. In patients who presented with dialysis dependent renal failure $(n=39)$ the patient and renal survival were 65 and $8 \%$ at 1 year and 36 and $5 \%$ at last follow-up. Interestingly, all patients who required immediate dialysis and had $100 \%$ crescents on renal biopsy remained dialysis dependent. Their conclusion was that plasma exchange and early immunosuppression are recommended in the treatment of patients with Good Pasture's Syndrome. If one does presume that the original reports prior to 1975 did indicate that the majority of patients with a diagnosis of Goodpasture's Syndrome had a fatal course, it would seem prudent to plasmapherese however this is also prior to the era of bolus methylprednisolone therapy in association with cytotoxic therapy.

The 5th commonest cause for plasma exchange is recurrent FSGS and we have anecdotal reports of benefit. The largest study was completed by Andresdottir [22]. There were 17 patients in which seven received plasma exchange and five of seven in the plasma exchange group entered remission with three of five still in a complete remission at a 2-year follow-up in contrast in the non-plasma exchange arm 10/10 lost their graft function.

The sixth indication was Cryoglobulinemia and there really has been no randomized control trials. It has largely been used on a mechanistic basis as discussed in a recent review [23]. The issue of plasma exchange for myeloma kidney has been addressed by several authors and there have been varying opinions. The largest randomized control trial $(n=97)$ was reported in 2005 in the Annals of Internal Medicine and in that randomized control trial, the patients with acute renal failure due to myeloma kidney received 5-7 plasma exchanges and the primary renal outcome was a composite of death, dialysis dependence or a creatinine clearance of less than $30 \mathrm{~mL} / \mathrm{min}$. In the plasma exchange (PLEX) arm $57.9 \%$ achieved the primary outcome whereas $69.2 \%$ of the non-PLEX arm did, but the difference was not significant although there was a trend for improvement in the plasma exchange arm [24]. It was concluded that plasma exchange for acute renal failure at the onset of myeloma is not associated with benefit in reducing the intention to treat primary outcome. There have been several recent reports most notably, the report by Leung et al. in Kidney International, of 40 patients they indicated that these patients who were biopsied and shown to have cast nephropathy, with a free light-chain elevation did show a good response of $50 \%$ with the use of plasma exchange in conjunction with their immunosuppressive therapy, however only $2 / 9$ or $22 \%$ were independent of dialysis [25]. Their response rate is identical to the response rate of the control group in the RCT by Clark et al. [24]. They are possibly not as good in terms of renal recovery and this may relate to the rapidity of onset in the Clark RCT versus the mixed picture of patients in the Leung study who are both early and late disease patients with both primary and recurrent renal involvement. The most cogent argument is that of Kastritis et al. in Hemotologica in 2007 in which they adopted the use of Bortezamib. Bortezamib with no PLEX in patients with acute renal failure at the onset of myeloma was associated with $80 \%$ renal recovery [26]. There is no debate that better randomized control trials are needed to clarify the role of this therapy in multiple myeloma but at the present time we would agree with the American Society of Apheresis and describe plasma exchange as having the suggestion of benefit for which existing evidence is insufficient to establish efficacy of benefit and hence plasma exchange is not indicated at this time for the treatment of patients who present with acute renal failure due to cast nephropathy at the onset of their myeloma [27].

\section{CONCLUSIONS}

The major renal indications for plasma exchange in 2010 reported by the CAG have both Level 1 (randomized control trial) and Level 2 (mechanistic) evidence. The commonest indication, adult TTP/HUS is justified by the results of a randomized control trial as well as the number two indication $\mathrm{C}$ and P ANCA Vasculitis with rapidly progressive glomerulonephritis $[8,15]$. Level 2 or mechanistic evidence is responsible for the number 3 indication, kidney transplant with removal of antibodies due to HLA hypersensitization or $\mathrm{ABO}$ incompatibility or acute humeral-rejection and for the fourth indication Goodpasture's Syndrome with the removal of the anti-GBM antibody and in FSGS the removal of a circulating humeral mediator of permeability and cryoglobulin in cryoglobulinemia. In terms of the CAG data the major nonindications for plasma exchange in 2010 were due to Level 1 evidence and this was the result of RCTs in myeloma and in lupus (and there were only two cases being treated in Canada in 2010) [24,28]. It appears that in 2010 most plasma exchange activity for renal indications is evidence based. 


\section{ACKNOWLEDGMENTS}

Thanks to Dr Gail Rock and members of the Canadian Apheresis Group for providing Registry data summarized in Table I. The contents of this manuscript were presented at the Therapeutic Apheresis Academy 2011.

\section{REFERENCES}

1. Lockwood CM, Boulton-Jones JM, Lowenthal RM, Simpson IJ, Peters DK. Recovery from Goodpasture's syndrome after immunosuppressive treatment and plasmapheresis. Br Med J 1975;2: 252-254.

2. Clark WF, Rock GA, Buskard N, Shumak KH, LeBlond P, Anderson D, Sutton DM. Therapeutic plasma exchange: an update from the Canadian Apheresis Group. Ann Inter Med 1999;131:453-462.

3. Moschcowitz E. An acute febrile pleiochromic anemia with hyaline thrombosis of the terminal arterioles and capillaries. An undescribed disease. Arch Internal Med 1925;36:89-93.

4. Gasser C, Gauthier E, Steck A, et al: Hamolytisch-uramische syndromes bilaterale nierenrindennekrosen bei akuten erworbenchen hamolytischen anamien. Schweiz Med Wschr 1955;85: 905-909.

5. Rubenstein MA, Kagan BM, MacGillviray MH, Merliss R, Sacks H. Unusual remission in a case of thrombotic thrombocytopenia purpura syndrome following fresh blood exchange transfusions. Annals Internal Med 1959;51:1409-1419.

6. Bukowski RM, King JW, Hewlett JS. Plasmapheresis in the treatment of thrombotic thrombocytopenic purpura. Blood 1977; 50:413-417.

7. Byrnes JJ, Khurana M. Treatment of thrombotic thrombocytopenic purpura with plasma. NEJM 1977;297:1386-1389.

8. Rock GA, Shumak KH, Buskard NA, Blanchette VS, Kelton JG, Nair RC, Spasoff RA; the Canadian Apheresis Study Group. Comparison of plasma exchange with plasma infusion in the treatment of thrombotic thrombocytopenia purpura. NEJM 1991;325:393-397.

9. Tsai H-M, Lian E C-Y. Antibodies to Von Willebrand factorcleaving protease in acute thrombotic thrombocytopenic purpura. NEJM 1998;339:1585-1594.

10. Furlan M, Robles R, Galbusera M, Remuzzi G, Kyrle PA, Brenner B, Krause M, Scharrer I, Aumann V, Mittler U, Solenthaler M, Lammle B. Von Willebrand factor-cleaving protease in thrombotic thrombocytopenic purpura and the hemolytic-uremic syndrome. N Engl J Med 1998;339:1578-1584.

11. Vesely SK, George JN, Lammle B, Studt J-D, Alberio L, El-Harake MA, Raskob GE. ADAMTS13 activity in thrombotic thrombocytopenic purpura-hemolytic uremic syndrome: relation to presenting features and clinical outcomes in a prospective cohort of 142 patients. Blood 2003;102:60-68.

12. Amorosi EL, Ultmann JE. Thrombotic thrombocytopenic purpura: report of 16 cases and review of literature. Medicine (Baltimore) 1966;45:139-159.

13. Cohen JA, Brecher ME, Bandarenko N. Cellular source of serum lactate dehydrogenase elevation in patients with thrombotic thrombocytopenic purpura. J Clin Apher 1998;13: $16-19$.

14. Fujimara Y, Matsumoto M, Yagi H.Thrombotic microangiopathy. In: Tanaka K, Davie EW, editors. Recent Advances in
Thrombosis and Hemostasis, 1st ed. Tokyo, Japan: Springer 2008. p XXI, pp. 625-639.

15. Jayne DR, Gaskin G, Rasmussen N, Abramowicz D, Ferrario F, Guillevin L, Mirapeix E, Savage CO, Sinico RA, Stegeman CA, Westman KW, van der Woude FJ, deLind van Wijngaarden RA, Pusey CD; European Vasculitis Study Group. Randomized trial of plasma exchange or high-dosage methylprednisolone as adjunctive therapy for severe renal vasculitis. J Am Soc Nephrol 2007; 18:2180-2188.

16. Montgomery RA, Lonze BE, King KE, Kraus ES, Kucirka LM, Locke JE, Warren DS, Simpkins CE, Dagher NN, Singer AL, Zachary AA, Segev DL. Desensitization in HLA-incompatible kidney recipients and survival. N Engl J Med 2011;365: 318-326.

17. Tobian AA, Shirey RS, Montgomery RA, Ness PM, King KE. The critical role of plasmapheresis in ABO-incompatible renal transplantation. Transfusion 2008;48:2453-2460; Review.

18. Karthikeyan V, Parasuraman R, Shah V, Vera E, Venkat KK. Outcome of Plasma exchange therapy in thrombotic microangiopathy after renal transplantation. Am J Transplant 2003;3: 1289-1294.

19. Swainson CP, Robson JS, Urbaniak SJ, Keller AJ, Kay AB. Treatment of Goodpasture's disease by plasma exchange and immunosuppression. Clin Exp Immunol 1978;32:233-242.

20. Johnson JP, Moore J Jr., Austin HA III, Balow JE, Antonovych TT, Wilson CB. Therapy of anti-glomerular basement membrane antibody disease: analysis of prognostic significance of clinical, pathologic and treatment factors. Medicine (Baltimore) 1985;64:219-227.

21. Levy JB, Turner AN, Rees AJ, Pusey CD. Long-term outcome of anti-glomerular basement membrane antibody disease treated with plasma exchange and immunosuppression. Ann Intern Med 2001; 134:1033-1042.

22. Andresdottir MB, Ajubi N, Croockewit S, Assmann KJ, Hibrands LB, Wetzels JF. Recurrent focal glomerulosclerosis: natural course and treatment with plasma exchange. Nephrol Dial Transplant 1999;14:2650-2656.

23. Rockx MA, Clark WF. Plasma exchange for treating cryoglobulinemia: a descriptive analysis. Transfus Apher Sci 2010;42: 247-251.

24. Clark WF, Stewart AK, Rock GA, Sternbach M, Sutton DM, Barrett BJ, Heidenheim AP, Garg AX, Churchill DN; Canadian Apheresis Group. Plasma exchange when myeloma presents as acute renal failure: a randomized, controlled trial. Ann Intern Med 2005;143:777-784. Erratum in: Ann Intern Med 2007;146: 471.

25. Pillon L, Sweeting RS, Arora A, Notkin A, Ballard HS, Wieczorek RL, Leung N. Approach to acute renal failure in biopsy proven myeloma cast nephropathy: is there still a role for plasmapheresis? Kidney Int 2008;74:956-961.

26. Kastritis E, Anagnostopoulos A, Roussou M, Gika D, Matsouka C, Barmparousi D, Grapsa I, Psimenou E, Bamias A, Dimopoulos MA. Reversibility of renal failure in newly diagnosed multiple myeloma patients treated with high dose dexamethasone-containing regimens and the impact of novel agents. Haematologica 2007;92:546-549.

27. Clark WF, Garg AX. Plasma exchange for myeloma kidney: cast(s) away? Kidney Int 2008;73:1211-1213.

28. Lewis EJ, Hunsicker LG, Lan SP, Rohde RD, Lachin JM. A controlled trial of plasmapheresis therapy in severe lupus nephritis. The Lupus Nephritis Collaborative Study Group. N Engl J Med 1992;326:1373-1379. 